\title{
Effect of Heating Temperature on the Grain Size and Titanium Solid-Solution of Titanium Microalloyed Steels
}

\author{
Jianjing Wang1,2, Yonglin Kang1, Caishui Yang1, Yuexiang Wang2 \\ ${ }^{1}$ University of Science and Technology Beijing, Beijing, China \\ ${ }^{2}$ Laiwu Branch of Shandong Iron \& Steel Co. Ltd., Jinan, China \\ Email: bandaisuo@126.com
}

How to cite this paper: Wang, J.J., Kang, Y.L., Yang, C.S. and Wang, Y.X. (2019) Effect of Heating Temperature on the Grain Size and Titanium Solid-Solution of Titanium Microalloyed Steels. Materials Sciences and Applications, 10, 558-567.

https://doi.org/10.4236/msa.2019.108040

Received: July 17, 2019

Accepted: August 17, 2019

Published: August 20, 2019

Copyright $\odot 2019$ by author(s) and Scientific Research Publishing Inc. This work is licensed under the Creative Commons Attribution International License (CC BY 4.0).

http://creativecommons.org/licenses/by/4.0/

\begin{abstract}
Through studying on the heating process of titanium microalloyed steels, the influence of heating temperature on the austenite grain size and the solid dissolution, precipitation law of Ti microalloying element were analyzed, and the results showed that, the austenite grain size increased with the increase of heating temperature, When the heating temperature reached $1050^{\circ} \mathrm{C}$ and $1250^{\circ} \mathrm{C}$, the austenite grains appeared the obvious coarsening process twice. $\mathrm{TiC}$ particles dissolved gradually as the heating temperature increased. When the heating temperature rose to $1100^{\circ} \mathrm{C}, \mathrm{TiC}$ particles disappeared basically, When the heating temperature rose to $1250^{\circ} \mathrm{C}$, TiN particles began to be dissolved and grow up.
\end{abstract}

\section{Keywords}

Titanium Microalloying, Heating Temperature, Austenite Grains, Solid-Solution, Precipitation

\section{Introduction}

In the rolling process of titanium microalloyed steels, the heating system has an important effect on the original austenite grains and solid solution of Titanium microalloying. Due to the inheritance of austenite grains, the heating process will affect the size of austenite grains and distribution of titanium particles during rolling process, thus affecting the microstructure and properties of as-rolled products. And so the study on the heating process of titanium microalloyed steels and the establishing of a reasonable heating system has an important influence on the controlled rolling and cooling processes. 
The main factors affecting the size of austenite grains during the heating process, include the heating temperature, the holding time and the contents of alloying elements. Through further analysis on the Zener model [1], Gladman [2] And Hillert [3] studied the effect of precipitation particles on the size of austenite grains, and proposed a method for predicting the size of austenite grains.

Through analysis on the size of austenite grains during the heating process of continuous casting slabs, some scholars [4] derived the empiric formula, the formula of austenite grain growing related to chemical composition was derived, but the effect of Ti on the activation energy of grain growth was not analyzed.

The second-phase particle precipitation of Ti element is usually divided into two stages: the precipitation of TiN particles occurs at high temperatures and the strain-induced precipitation of $\mathrm{TiC}$ particles occurs at low temperatures. Similarly, during the heating process, the influence of Ti-bearing precipitated particles on the grain coarsening also has two stages. In this paper, the growth of austenitic grain size for the microalloyed steels with $\mathrm{Ti}$ content of $0.05 \%$ were studied in the paper.

\section{Test Materials and Methods}

The test steel is titanium microalloyed Q345D, its chemical composition is detected by photoelectric direct reading spectrometer (M12). Its chemical composition was shown in Table 1 .

The test steel was taken from $1500 \mathrm{~mm}$ continuous rolling production line of laigang group steel mill, A sample of $16 \mathrm{~mm} \times 16 \mathrm{~mm} \times 10 \mathrm{~mm}$ in size was processed. Then the sample was heated to a set temperature $\left(850^{\circ} \mathrm{C}, 900^{\circ} \mathrm{C}\right.$, $950^{\circ} \mathrm{C}, 1000^{\circ} \mathrm{C}, 1050^{\circ} \mathrm{C}, 1100^{\circ} \mathrm{C}, 1150^{\circ} \mathrm{C}, 1180^{\circ} \mathrm{C}, 1200^{\circ} \mathrm{C}, 1250^{\circ} \mathrm{C}$ ), and immediately quenched with ice brine after holding for 30 minutes. After grinding and polishing, the quenched specimen were treated with a solution of saturated picric acid and a small amount of detergent, with the constant temperature of $60^{\circ} \mathrm{C}$, to display the original austenite microstructure, and then the austenite grain size was measured by truncation in the Image-pool software, and the number of grains measured was more than 300 to ensure the accuracy of the data.

A thermodynamic formula was used to calculate the solid solution law of $\mathrm{Ti}$ during austenization process of the test steel under equilibrium conditions. The size, morphology and distribution of the particles under different heating temperatures were observed by transmission electron microscopy. And the components of the particles were analyzed by EDS.

\section{Effect of Heating Temperature on Austenite Grain Size}

Figure 1 shows the original austenite microstructure of test steel after holding for 30 minutes at different heating temperatures.

As can be seen from Figure 1, when the heating temperature reaches $850^{\circ} \mathrm{C}$ and $950^{\circ} \mathrm{C}$, the austenite grains are small and uniform, and as the heating 
Table 1. Chemical compositions of test steel (Wt \%).

\begin{tabular}{cccccccc}
\hline $\mathrm{C}$ & $\mathrm{Si}$ & $\mathrm{Mn}$ & $\mathrm{P}$ & $\mathrm{S}$ & $\mathrm{Als}$ & $\mathrm{Ti}$ & $\mathrm{N}$ \\
\hline 0.15 & 0.28 & 0.65 & 0.013 & 0.004 & 0.023 & 0.048 & 0.0028 \\
\hline
\end{tabular}
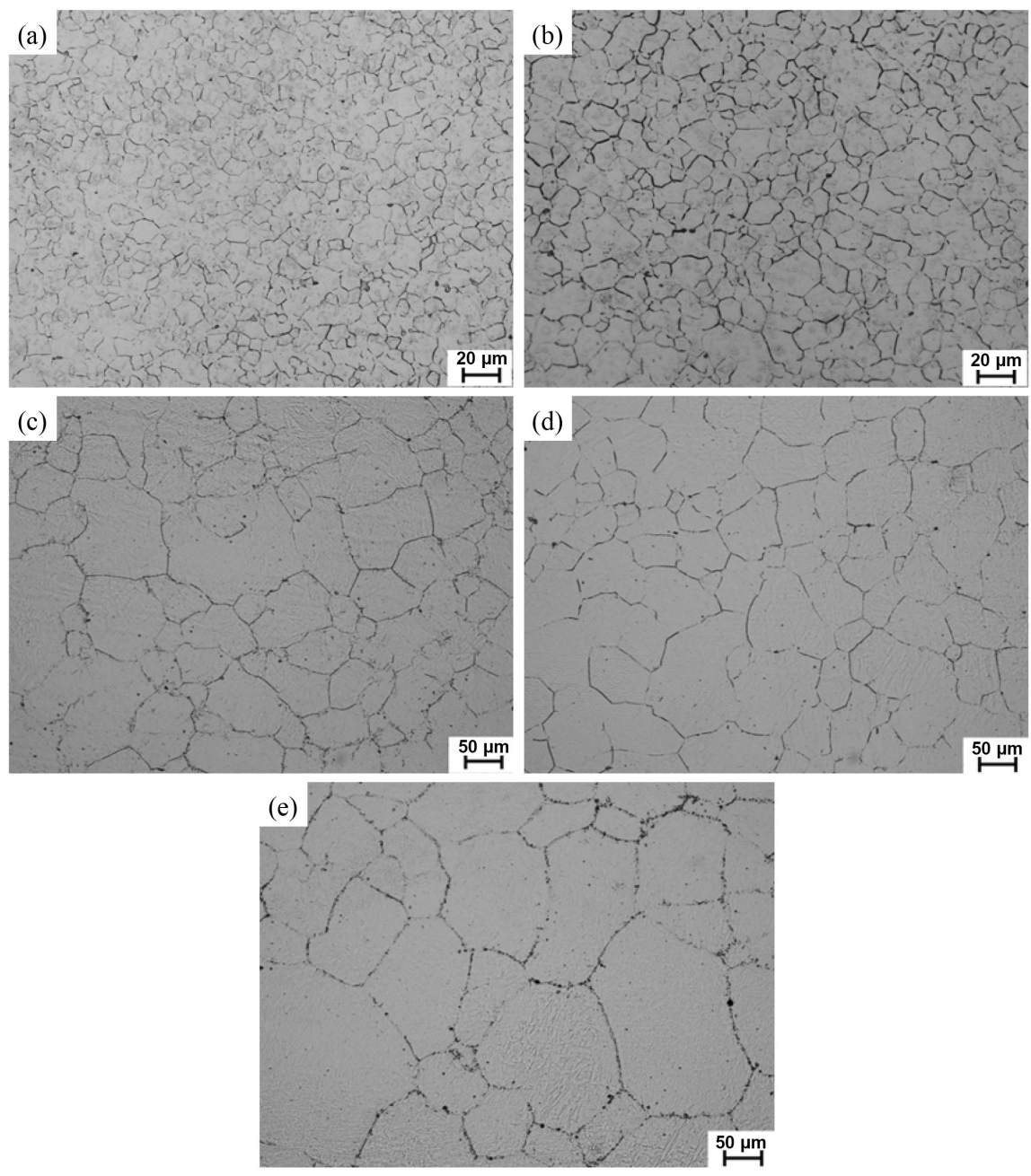

Figure 1. The original austenite grain microstructure under different heating temperatures. (a) $850^{\circ} \mathrm{C}$; (b) $950^{\circ} \mathrm{C}$; (c) $1050^{\circ} \mathrm{C}$; (d) $1150^{\circ} \mathrm{C}$; (e) $1250^{\circ} \mathrm{C}$.

temperature increases, the austenite grains grow slowly. When the heating temperature is lower, the fine $\mathrm{TiC}$ particles in the test steel are dispersed in austenitic grains, preventing austenitic grains from growing. When the heating temperature rises to $1050^{\circ} \mathrm{C}$, the austenite grains grow significantly, and some large-sized grains appear, the non-uniform distribution of grain size is observed, and there is a tendency for large grains begin to swallow small grains. At the moment, the $\mathrm{TiC}$ precipitated particles in austenite grains are basically dissolved, and thus its pinning force on austenite grain growth is greatly reduced, and a few grains grew abnormally. At heating temperature of $1150^{\circ} \mathrm{C}$, the growth of austenite grains are not more significant due to the pinning effect of TiN particles at the boundary of austenite grains. When the heating temperature rises to $1250^{\circ} \mathrm{C}$, the TiN 
particles at the austenitic boundary are dissolved, and its pinning force is greatly reduced, so the austenitic grains grow abnormally.

Table 2 shows the average size of austenitic grains in test steel after holding for 30 minutes at different heating temperatures.

Figure 2 shows the tendency of austenitic grain size changing with temperature. It can be seen from Figure 2, with the increase of temperature, there are two coarsening temperatures for the test steel, which are $1050^{\circ} \mathrm{C}$ and $1250^{\circ} \mathrm{C}$, respectively,. When the heating temperature is lower than $1000^{\circ} \mathrm{C}$, the austenite grains grow slowly. When the temperature rises to $1050^{\circ} \mathrm{C}$, the austenite grains grow up suddenly, the size increased from $24.7 \mu \mathrm{m}$ to $63.7 \mu \mathrm{m}$. When the temperature rises from $1050^{\circ} \mathrm{C}$ to $1200^{\circ} \mathrm{C}$, the austenite grain growth tends to slow down again. When the temperature rises to $1250^{\circ} \mathrm{C}$, the austenite grains grow rapidly, the size increased from $80.4 \mu \mathrm{m}$ to $107.9 \mu \mathrm{m}$.

Figure 3 shows the distribution of austenite grain size after holding for 30 minutes at different heating temperatures. It can be seen from Figure 3, the size distribution of austenite grains is close to the normal distribution. The normal distribution can well describe the grain size during grain growth [5]. When the heating temperatures are $850^{\circ} \mathrm{C}$ and $1050^{\circ} \mathrm{C}$, the austenitic grain size distribution is in line with the normal distribution. When the heating temperature is $1250^{\circ} \mathrm{C}$, the austenitic grain size distribution is relatively dispersed, and some grains grow up abnormally. When the heating temperature is $850^{\circ} \mathrm{C}$, the austenite grains are basically less than $20 \mu \mathrm{m}$, and most grains are between $5 \mu \mathrm{m}$ and $15 \mu \mathrm{m}$ in size; When the heating temperature rises to $1050^{\circ} \mathrm{C}$, most austenite grains are between $40 \mu \mathrm{m}$ and $80 \mu \mathrm{m}$ in size, but due to the dissolution of $\mathrm{TiC}$ particles, The large-sized grains larger than 100 microns, which account for $10 \%$ of the total grain size, appears. When the heating temperature rises to $1250^{\circ} \mathrm{C}$, the austenite grains are coarsening, and more than $50 \%$. Of the grainssize is larger than $100 \mu \mathrm{m}$.

\section{The Effect of Heating Temperature on the Solid Dissolution and Precipitation of Ti Element}

During the controlled rolling and cooling processes of titanium microalloyed steel, Ti precipitated particles mainly include TiN, Ti4C2S2, and TiC [6]. Because the sulfur contentl is relatively lower, the typical particles are mainly TiN and $\mathrm{TiC}$ particles, as shown in Figure 4. Figure 4(a) shows a dispersed fine precipitated particle with size less than $10 \mathrm{~nm}$. Analysis on the selected region through the EDS spectrum, these fine precipitated particles are TiC; Figure 4(b) is a precipitated particle with size between 100 and $200 \mathrm{~nm}$. EDS spectroscopic

Table 2. Austenite grain sizes at different heating temperatures.

\begin{tabular}{lcccccccccc}
\hline Heating temperature $/{ }^{\circ} \mathrm{C}$ & 850 & 900 & 950 & 1000 & 1050 & 1100 & 1150 & 1180 & 1200 & 1250 \\
\hline Average grain size/ $\mu \mathrm{m}$ & 10.03 & 11.42 & 12.71 & 24.68 & 63.69 & 68.11 & 72.63 & 75.88 & 80.4 & 107.9 \\
\hline
\end{tabular}




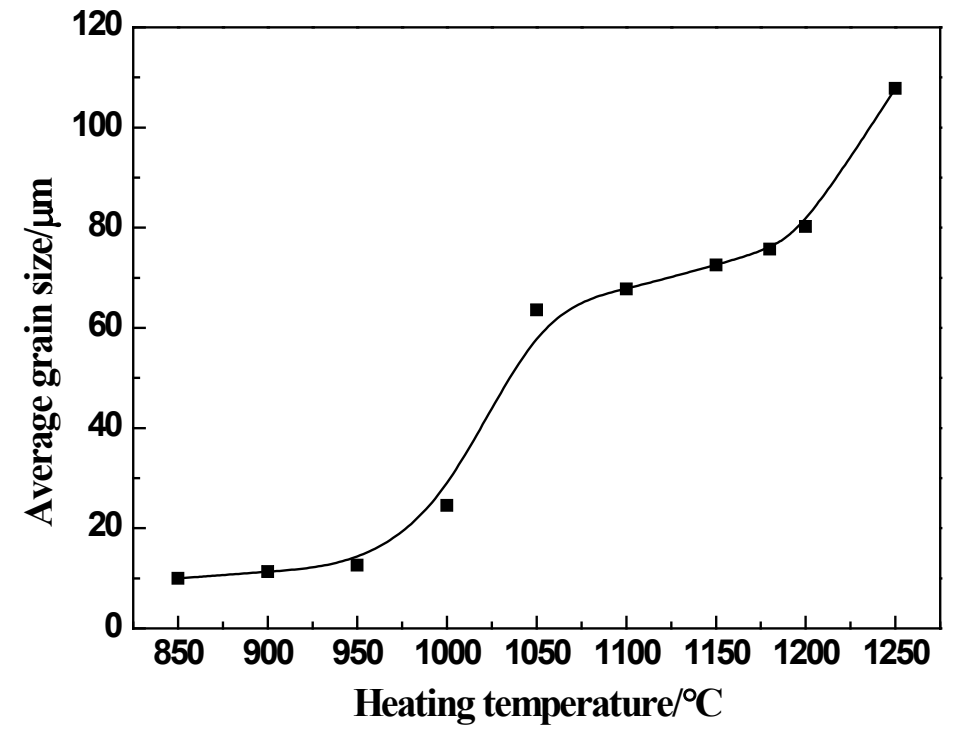

Figure 2. Effect of heating temperature on the size of austenite grains.

(a)

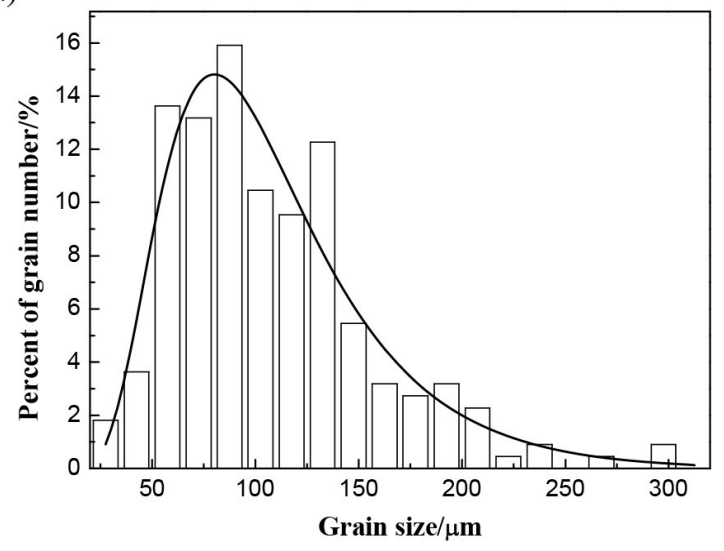

(b)

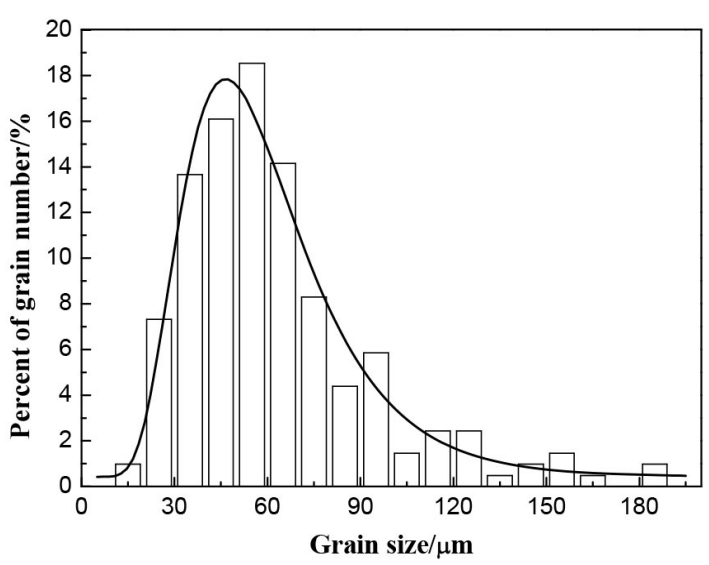

(c)

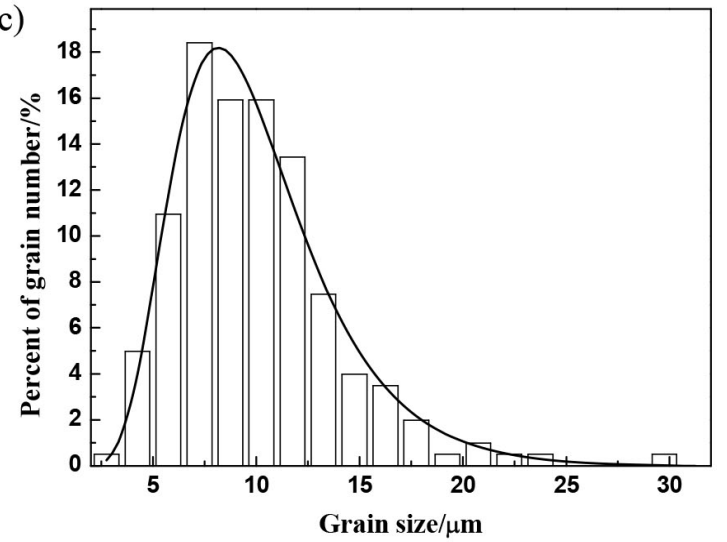

Figure 3. Austenite grain size distribution at different temperatures. (a) $850^{\circ} \mathrm{C}$; (b) $1050^{\circ} \mathrm{C}$; (c) $1250^{\circ} \mathrm{C}$.

analysis shows that the precipitated particles are carbonitrides of $\mathrm{Ti}$, and further analysis by EDR calibration shows that the precipitated particles are TiN particles with face-centered cubic. 

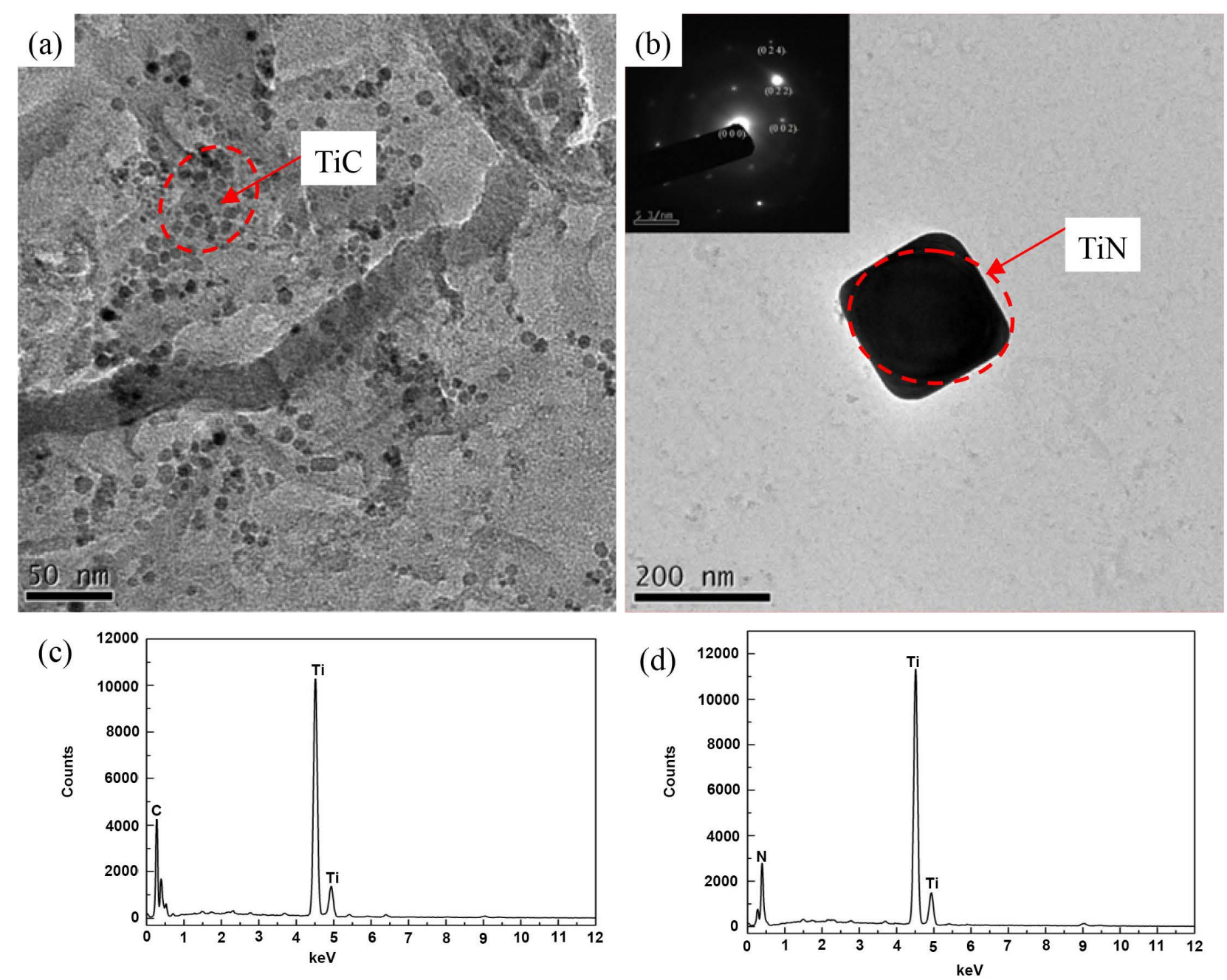

Figure 4. Two typical particles precipitated by Ti. (a) Smaller particles; (b) Bigger particles; (c) and (d) are EDS analysis of corresponding regions of (a) and (b).

Figure 5 is the distribution of the size and morphology of Ti-precipitated particles prepared by extraction complex at different heating temperatures. It can be seen from Figure 5 when the heating temperature reaches $850^{\circ} \mathrm{C}$, there are a large number of $\mathrm{TiC}$ precipitate with size less than $10 \mathrm{~nm}$. which have a strong effect on grain coarsenization. When the heating temperature rises to $1000^{\circ} \mathrm{C}$, the spherical fine $\mathrm{TiC}$ particles are significantly reduced and the size increases to $10-20 \mathrm{~nm}$; When the heating temperature rises to $1100^{\circ} \mathrm{C}$, the small spherical TiC particles basically disappear and the austenite grains are coarsened, but there are still TiN particles with size between $50 \mathrm{~nm}$ and $100 \mathrm{~nm}$, and these particles still have some hindrance to the growth of austenite grains.; When the heating temperature rises to $1200^{\circ} \mathrm{C}$, the precipitated TiN with size mainly between $50 \mathrm{~nm}$ and $200 \mathrm{~nm}$; When the heating temperature rises to $1250^{\circ} \mathrm{C}$, the number of TiN particles is significantly reduced, and the precipitated particles mostly grows to $200-500 \mathrm{~nm}$, whose effect of preventing austenite grain growth is greatly weakened, and the austenite grains are significantly coarsened. 

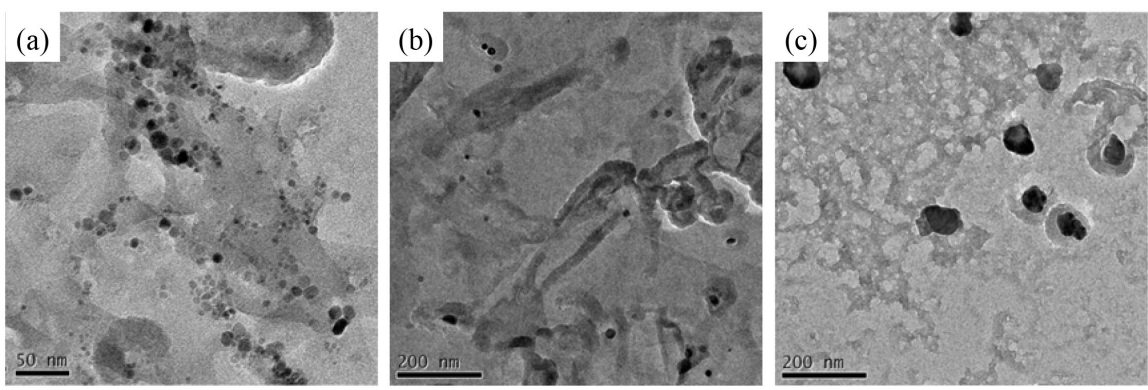

(d)

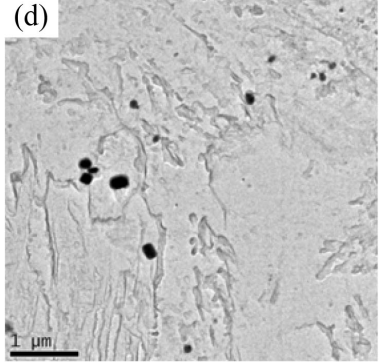

(e)

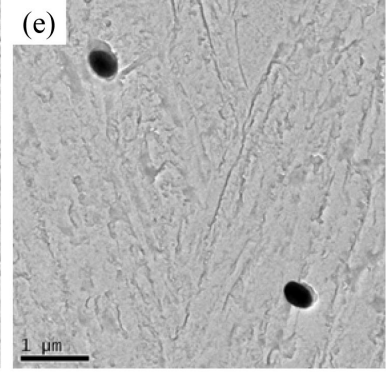

Figure 5. The morphology of precipitated particles at different heating temperatures. (a) $850^{\circ} \mathrm{C}$; (b) $1000^{\circ} \mathrm{C}$; (c) $1100^{\circ} \mathrm{C}$; (d) $1200^{\circ} \mathrm{C}$; (e) $1250^{\circ} \mathrm{C}$.

\section{Results Analysis and Discussion}

The coarsening process of austenite grains during heating process is related to the alloying elements in steel. The precipitated particles of alloy elements have a strong hindrance effect on the growth of austenite grains. When the driving force of grain growth reaches a thermodynamic equilibrium with the pinning force of precipitated particles, Austenitic grains grown normally. Therefore, the austenite grain size prediction model can be expressed by the following formula:

$$
R=A \cdot r / f
$$

In the formula: $\mathrm{R}$ is the austenite grain size, $\mathrm{A}$ is the constant, $\mathrm{R}$ is the average size of the precipitated particles, and $f$ is the the volume fraction of precipitated particles. At present, many scholars have analyzed the value of the constant A, The value of A in the Zener model [1] is 0.75; The value of A in Gladman model [2] is between 0.05 and 0.26; The value of A in Hillert model [3] is 0.44, the austenite grains grow normally, the value of $\mathrm{A}$ is 0.44 to 0.67 , and the austenite grains grow abnormally.

Austenite grain size is related to the size and volume fraction of the precipitated particles. Both TiC and TiN particles precipitated in the test steel after being rolled.. As the heating temperature increases, the dispersed fine $\mathrm{TiC}$ particles are gradually dissolved. When the heating temperature rises to $1100^{\circ} \mathrm{C}$, the $\mathrm{TiC}$ particles are basically dissolved, the pinning effect of $\mathrm{TiC}$ on austenite grains disappears and the austenite grains change coarsened. With the further increase of heating temperature, the growth of austenite grains is not clear due to Due to the nail effect of TiN precipitates particles. When the temperature rises to $1250^{\circ} \mathrm{C}$, the volume fraction of TiN precipitated particles is significantly reduced, their size is increased, and the nail effect on austenite grains is signifi- 
cantly reduced, the austenite grains are coarsened.

At present, many scholars have studied the solid solution behavior of Ti element in austenite. Among them, the solid solubility product of TiN in austenite can be expressed by the formula proposed by Kunze et al. [7], The solid solubility product of $\mathrm{TiC}$ in austenite can be expressed by the formula proposed by Irvine et al. [8], they are as follows:

$$
\begin{gathered}
\lg ([\% T i][\% N])_{\gamma}=5.19-15490 / T \\
\lg ([\% T i][\% C])_{\gamma}=2.75-7000
\end{gathered}
$$

In the formula: [ $T i][N]$ And $[C]$ is the amount of element dissolved in austenite. $T$ is the solid solution temperature $(\mathrm{K})$. Based on the formula, the complete solution temperature of $\mathrm{TiN}$ and $\mathrm{TiC}$ is respectively $1450.7^{\circ} \mathrm{C}$ and $1132.3^{\circ} \mathrm{C}$. which are all higher than the coarsening temperature of austenitic grains. When the precipitated particles are dissolved and grow to a certain extent, the pinning force will be reduced to a certain critical value, so that the austenite grains will grow, which is consistent with the study results from Cuddy et al. [9].

The austenite grain size in the heating process can also be expressed by the Arrhenius-type formula [10]:

$$
d=A \exp \left(-\frac{Q}{R T}\right) t^{n}
$$

In the formula: $D$ is the average grain size, $A, N$ are the constant, $Q$ is the grain growth activation energy $(\mathrm{J} / \mathrm{mol})$, and $R$ is the gas constant $(8.314$ $\left.\mathrm{J} \cdot \mathrm{mol}^{-1} \cdot \mathrm{K}^{-1}\right), T$ is the holding time(s). Considering that the heating times of the test steel in this paper are the same, the austenite grain size in this paper is only related to the heating temperature and alloying elements. Therefore, the empirical formula can be simplified as follows:

$$
d=B \exp \left(-\frac{Q}{R T}\right)
$$

For general carbon steels, the grain growth activation energy $Q$ is a constant. However, for microalloyed steels, $Q$ is a value related to the content of alloy elements. The influence of alloying elements on $Q$ is mainly by the pinning precipitated particles which is based on the migration of austenite grain boundary. Therefore, the main factor affecting $Q$ value is basically the precipitation particles in steel. In this paper, there are two kinds of precipitated particles in titanium microalloyed steel. The solution temperatures of the two precipitating particles are quite different, and there is a significant two-stage precipitating process. Therefore, the influence of precipitated particles on the growth of austenitic grains also has obvious two-stage effect, and this is consistent with the results in Figure 2. And Formula 5 was used to fit the normal growth process of austenite grains in two stages, Further analysis of the influence of precipitated particles on $Q$ value, as shown in Figure 6. It can be seen from the figure that, when the heating temperature is lower, the grain growth activation energy of the 


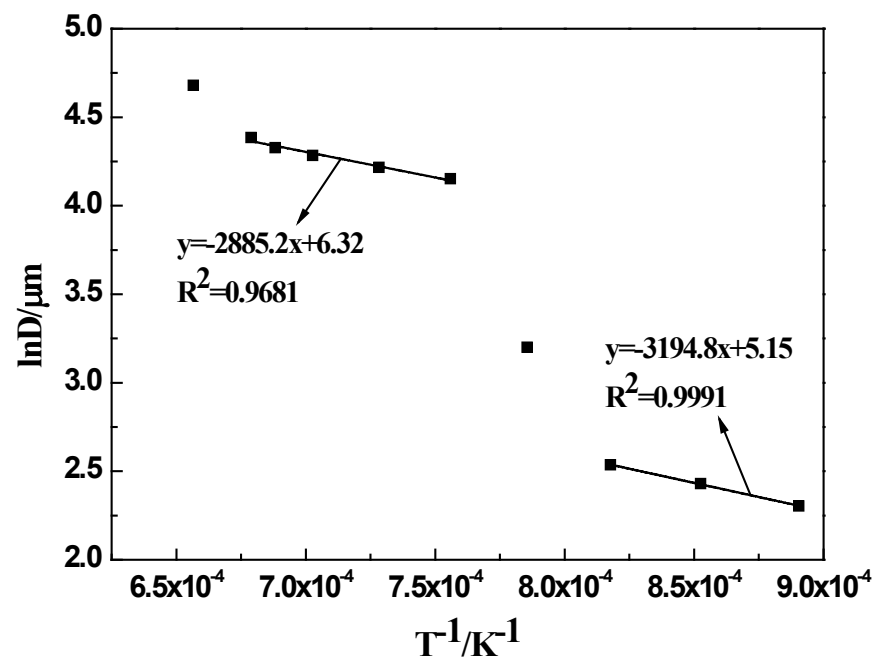

Figure 6. Relationship between reheating temperature and austenite grain size.

test steel is higher, which is $26,561 \mathrm{~J} / \mathrm{mol}$; When the heating temperature is higher, $\mathrm{TiC}$ particles have been dissolved and the activation energy value $\mathrm{Q}$ is reduced to $23,987 \mathrm{~J} / \mathrm{mol}$. Therefore, it can be determined that it is not the alloy itself that can affect growth activation., but the precipitated particles in the steel. Among them, $\mathrm{TiC}$ particles contribute $2574 \mathrm{~J} / \mathrm{mol}$ to the activation energy.

During the heating process of titanium microalloying steel, the choice of heating temperature is very important. If the heating temperature is too high, the original austenite grains will be coarsening, and TiN precipitated particles also can fully grow up. During the rolling process, The effect of restraining austenite grain growth is greatly reduced, resulting in the coarsening of grains. If the heating temperature is too low, the precipitated TiC particles can not be fully dissolved. It greatly weakens the pull and nail action of solute atoms in the subsequent rolling process and the inhibition of austenite grain crystallization. From the above experimental analysis results, it can be seen that, when the heating temperature is between $1180^{\circ} \mathrm{C}$ and $1200^{\circ} \mathrm{C}$, the TiC particles are fully dissolved and the austenite grains are not obviously coarsened.

\section{Conclusions}

Through the study on the heating process of titanium microalloyed Q345D steel, the effect of heating temperature on the size of austenite grains in the test steel and the solid dissolution and precipitation law of Ti microalloying element were analyzed, and the following conclusions can be drawn:

1) The size of austenite grains in the test steel increases with the increase of the heating temperature. When the heating temperature is $1050^{\circ} \mathrm{C}$ and $1250^{\circ} \mathrm{C}$, the austenitic grains appear to be significantly coarsened, and the austenite grains grow up. The growth process of austenite grains has obvious two-stage characteristics. The heating temperature of the test steel should be controlled at $1180^{\circ} \mathrm{C}-1200^{\circ} \mathrm{C}$. 
2) There are two types of Ti precipitated particles in the test steel. With the increase of heating temperature, the $\mathrm{TiC}$ particles are gradually dissolved. When the heating temperature rises to $1100^{\circ} \mathrm{C}$, the $\mathrm{TiC}$ particles basically disappear; When the heating temperature rises to $1250^{\circ} \mathrm{C}$, TiN particles begin to be dissolved and grow up. The two-stage solid solution of the precipitated particles corresponds to the two-stage growth process of austenite grains.

3) Fitting the grain size law of austenite in two stages respectively, it was obtained that, the activation energies of grain growth in the two stages were 265.6 $\mathrm{KJ} / \mathrm{mol}$ (at low temperature) and $239.8 \mathrm{KJ} / \mathrm{mol}$ (at high temperature), respectively, and the contribution of $\mathrm{TiC}$ particles to the activation energies was 25.8 $\mathrm{KJ} / \mathrm{mol}$.

\section{Conflicts of Interest}

The authors declare no conflicts of interest regarding the publication of this paper.

\section{References}

[1] Zener, C. (1948) Quoted by C.S. Smith. Trans AIME, 175, 15-51.

[2] Gladman, T. and Pickering, F.B. (1967) Grain-Coarsening of Austenite. The Iron and Steel Institute of Japan, 205, 653-664.

[3] Hillert, M. (1965) On the Theory of Normal and Abnormal Grain Growth. Acta Metallurgica, 13, 227-238. https://doi.org/10.1016/0001-6160(65)90200-2

[4] Lee, S.J. and Lee, Y.K. (2008) Prediction of Austenite Grain Growth during Austenitization of Low Alloy Steels. Materials \& Design, 29, 1840-1844.

https://doi.org/10.1016/j.matdes.2008.03.009

[5] Kurtz, S.K. and Carpay, F.M.A. (1980) Microstructure and Normal Grain Growth in Metals and Ceramics. Part I. Theory. Journal of Applied Physics, 51, 5725-5744. https://doi.org/10.1063/1.327580

[6] Zhou, J., Kang, Y. and Mao, X. (2008) Precipitation Characteristic of High Strength Steels Microalloyed with Titanium Produced by Compact Strip Production. Journal of University of Science and Technology Beijing, Mineral, Metallurgy, Material, 15, 389-395. https://doi.org/10.1016/S1005-8850(08)60074-2

[7] Kunze, J. (1991) Solubility of Titanium Nitride in Delta Iron. Steel Research, 62, 430-432. https://doi.org/10.1002/srin.199100423

[8] Irvine, K.J., Pickering, F.B. and Gladman, T. (1967) Grain-Refined C-Mn Steels. The Iron and Steel Institute of Japan, 205, 161-182.

[9] Cuddy, L.J. and Raley, J.C. (1983) Austenite Grain Coarsening in Microalloyed Steels. Metallurgical Transactions A, 14, 1989-1995. https://doi.org/10.1007/BF02662366

[10] Zhang, S.S., Li, M.Q., Liu, Y.G., et al. (2011) The Growth Behavior of Austenite Grain in the Heating Process of 300M Steel. Materials Science and Engineering: $A$, 528, 4967-4972. https://doi.org/10.1016/j.msea.2011.02.089 